\title{
Risks of Enterprise Merger \& Purchase and the Prevention
}

\author{
Aizhong Chen \\ School of Business Management, Shandong University of Fiance, Jinan 250014, China
}

\begin{abstract}
Enterprise merger \& purchase is a complex systematic project. It concerns interests of many parts. In China, risks of enterprise merger \& purchase include systematic risk, evaluating risk, financing risk, operational risk, corporate culture risk, and legal risk. These risks directly influence the merger \& purchase activities. Therefore, we should deal with them carefully, adopt prevention measures, and guarantee the success of merger \& purchase.
\end{abstract}

Keywords: Enterprise merger \& purchase, Risk, Prevention

Enterprise merger \& purchase is a noticeable economic phenomenon in China today. It is also a hot and focus of different fields in China. Along with the development of market economy in China, the tide of enterprise merger \& purchase is coming like a rising wind and scudding clouds. However, behind the tide of enterprise merger \& purchase, there is failure case sometimes. Therefore, risks of merger \& purchase deserve more attentions from people.

\section{Risks of enterprise merger \& purchase}

Enterprise merger \& purchase is a complex systematic project. It concerns interests of many parts. In China, risks of enterprise merger \& purchase include systematic risk, evaluating risk, financing risk, operational risk, corporate culture risk, and legal risk.

\subsection{Systematic risk}

Systematic risk means the harmful influence on merger \& purchase caused by the uncertainty of system. Although for most enterprises the merger \& purchase activities are kind of spontaneous behaviors in order to adapt to the requirements of market based on their real needs, some are directly controlled or pushed by the government who orders advantage enterprises to help disadvantage enterprises in many ways. In the second situation, both the advantage enterprise and the disadvantage enterprise do not have the motive to achieve merger \& purchase due to the lack of common interests. So, they can not understand clearly the business management and the development strategy after the merger \& purchase action. Therefore, the enterprise development idea can not be adjusted in time. As a result, this kind of merger \& purchase has a potential systematic risk.

\subsection{Evaluating risk}

Before the merger \& purchase, it is necessary to evaluate and predict the target enterprise's operations, finance, and future income, and take the result as a cause to determine the merger \& purchase action or the value of target enterprise. The uncertainty of evaluation and prediction and the asymmetry of information contribute to the emergence of evaluating risk.

\subsection{Financing risk}

Enterprise merger \& purchase needs amounts of capitals. The purchaser realizes the merger \& purchase sometimes based on its capitals, sometimes by financing lever, and sometimes by loans. No matter which way the purchaser takes, risks are inevitable. If the purchaser chooses to obtain capitals by loans and hopes to gain profits after the merger \& purchase action, the result is uncertain. Therefore, only if the merger \& purchase can realize higher ratio of return, can the purchaser gain profits from the action. Otherwise, the purchaser may confront bankruptcy because of worse capital structure, and higher liability ratio.

\subsection{Operational risk}

Operational risk means the harmful influence caused by problems in operations. In specific, it refers that the purchaser fails to achieve a coordinative effect among operations, finance, and market shares, and can not realize the expected effect, and even suffers from the new enterprise obtained by the merger \& purchase. In detail, after the merger \& purchase action, no expected finance coordinative effect appears. The enterprise's financial ability is not improved. And no low-cost and effective re-allocation is realized in the new enterprise. Besides, the former marketing channels are changed and the market shares become less, what affect the supposed effect. What's more, the new enterprise after the merger \& purchase action may come across the non-economic problem of scale.

\subsection{Corporate cultural risk}

Because every enterprise has different internal and external environments, the different business ideas and ways 
contribute to the emergence of different corporate cultures. Whether the corporate cultures can realize the integration or not brings about new risks for enterprise merger \& purchase. If the corporate cultures can not adapt to each other, employees may feel at a loss in front of two kinds of corporate cultures. As a result, it will affect the expected goals of the merger \& purchase action.

\section{Measures for preventing and settling down risks of enterprise merger $\&$ purchase}

The enterprise faces up with lots of risks in the merger $\&$ purchase process. These risks will directly threaten the success of this action. Therefore, the enterprise should take care of every ring, adopt prevention measures, and ensure the success of merger \& purchase.

\subsection{Keep close eyes on China's macro economic situation and master the latest trend of policy}

The macro economic situation includes three aspects, namely degree of economic prosperity, economic cycle, laws and regulations. The degree of economic prosperity focuses on macro economy and industrial fluctuation. The economic cycle aims at researching the costs and the success possibilities of enterprise merger \& purchase at different stages. In general, at the start-up stage and the last ring of an economic cycle, the success possibilities of enterprise merger \& purchase are higher. And the costs are lower relatively. To study government laws and regulations and master the newest policies are also extremely important for enterprise merger \& purchase. It is inevitable for enterprise merger \& purchase action being restricted by laws and regulations. Only when the enterprise probes into relevant laws and regulations and behaves legally, can it escape from lawsuits and improve the possibility of success.

\subsection{The enterprise must possess the ability of absorb and consume the resources under control}

The purchaser should have strong economic power and possess necessary capitals, technologies, and management abilities in order to accomplish the merger \& purchase. The aim should be clear and the action must be in accord with state industrial policy. The purchaser has already formed the strong capability of market exploration and an effective management team.

\subsection{The purchaser should emphasize on the establishment and development of its chief business and core enterprise.}

Under the guidance of state industrial policy, the purchaser should constitute a clear and firm strategy for corporate development that can provide with direction for the merger \& purchase action.

2.4 Improve the information asymmetry and make proper evaluation on target enterprise's values and decrease costs and risks.

Information asymmetry is the primary reason for the emergence of evaluating risk. The purchaser should avoid a hostile merger \& purchase action. It is necessary to make detailed investigation and evaluation on target enterprise. The purchaser should retain investment bank to make up an overall plan for corporate development strategy, and perform a general analysis on target enterprise's industrial environment, financial situations, and operational abilities, and conclude a reasonable expect for target enterprise's future profitability. By this way, the evaluation is close to the real fact, which can help to decrease risks of stock price. In addition, different evaluation methods may result in different values even for the same target enterprise. The pricing methods for enterprise's values include the cash-flow method, the market price method, the P/E ratio method, the comparison of same industrial values, the book value method, and the liquidity value method. The purchaser can make choice according to the aim of merger \& purchase action, whether the target enterprise exists or not after the action, and the reliability of information. Besides, the purchaser can evaluate the target enterprise's values by a pricing model.

\subsection{Choose the most profitable way to accomplish the merger \& purchase}

Enterprise merger \& purchase way has two aspects of meanings. One is the payment way of capitals. The other is the choice of merger \& purchase direction. The payment can be finished by many ways. The purchaser can design a payment structure that includes cash payment, debt payment, and stock payment, which can satisfy different needs of enterprises in the merger \& purchase. The purchaser can make best use of corporate stocks and national stocks' profitable transfer and non-profitable transfer to realize a low-cost operation. As far as the direction of merger \& purchase is concerned, the purchaser can choose a horizontal merger \& purchase action, or a vertical one, or a mixed one, or an integrated one or a partial one, according to its development strategy. The purchaser should be cautious to take action for the enterprise merger \& purchase plan that has lower industrial correlation with itself.

\subsection{Emphasize on the effect of medium agency}

Enterprise merger \& purchase is a complex project. In order to guarantee necessary interests, realize considerable incomes, avoid risks, and achieve legal and scientific merger \& purchase action, it is necessary to employ experts and institutions from different fields, such as lawyers, registered accounts, valuers, and investment banks that are 
familiar with state industrial policies and possess experiences of operating capitals. These experts and institutions can make special investigations and provide with consulting advices that serve as powerful weapons in preventing risks. By this way, the merger \& purchase action will be easier. These medium agencies can help the enterprise to design the reengineering mode, make feasibility analysis, and constitute and implement reengineering scheme to a great degree.

\subsection{Analyze the differences of corporate cultures and achieve mutual understanding and communication}

The purchaser should make an overall and detained analysis on the natures and characteristics of corporate cultures in the two different enterprises. Understand target enterprise's local culture, history, founders' personalities, and the reliance of employees on corporate culture. Realize the mutual understanding and communication and avoid failures caused by cultural conflicts.

\section{References}

Chen, Guanting. (2004). An analysis of auditing alienation. Audit Research. No.5.

Du, Ying. \& Zhang, Jialin. (2003). Application of economic value added to corporation performance evaluation. The Theory and Practice of Finance and Economics. No.1.

Peng, Yilin. (2005). China's independent auditing institutions' characteristics, shortcomings, and measures for improvement. Academia Bimestris. No.3.

Zhang, Qian. (2004). Probe into problems in financial accounting under IT environment. Friends of Accounting. No.4.

Zhang, Xingen. \& Wang, Xiuli. (2003). On the quality characteristics of corporate finance. Accounting Research. No.9. 